\title{
DETERMINAÇĀO DO RENDIMENTO INSTRUMENTAL DA MINISTRAÇÃO DE MEDICAMENTOS POR VIA INTRAMUSCULAR EM PACIENTES HOSPITALIZADOS*
}

\author{
** Lidivina Horr \\ ** Eliana M. Faria \\ ** Ana Palma S. Camargo \\ ** Inês Maria Oro \\ *** Maria de Lourdes Souza
}

RBEn/05

HORR, L. e colaboradoras - Determinação do rendimento instrumental da ministração de medicamentos por via intramuscular em paciente hospitalizados. Rev. Bras. Ene.; DF, 31 : 478-495, 1978.

\section{I - INTRODUĢAO}

A ministração de medicamentos prescritos para pacientes hospitalizados, é uma atividade tradicionalmente atribuida aos profissionais da equipe de enfermagem. Entre as diversas vias pelas quais os medicamentos podem ser ministrados, escolheu-se para o presente estudo, a intramuscular (I.M.) para se determinar o rendimento instrumental.

Horta \& Teixeira (8) conceituam a injeção I.M. como sendo a "introdução de droga dentro do corpo muscular", mencionando no mesmo trabalho as características dos músculos indicados para esta finalidade: “a) corpo bem de- senvolvido; b) fácil acessibilidade; c) ausência de grandes vasos e nervos situados superficialmente".

Entretanto, vários fatores influenciam na escolha do local para a aplicação da injeção I.M. Kozier \& DuGas (9) os apontam como sendo: a idade do paciente, a quantidade de tecido muscular em que é possível aplicar-se uma injeção, a proximidade de nervos e vasos sangüíneos, o estado da pele ao redor da área da aplicação e a natureza do medicamento que se vai ministrar.

Os músculos das regiōes deltóide e dorso glúteo são os tradicionalmente utilizados para a aplicação da injeção I.M. Vários autores, porém, inuilcam os mús-

- Tema Livre apresentado no XXX CBEn - Belém - Pará - 1978.

* Moitrandas da UFSc.

*** Orientadora da pesquisa, na UFSC. 
HORR, L. e colaboradoras - Determinaçăo do rendimento instrumental da ministraçåo de medicamentos por via intramuscular em paciente hospitalizados. Rev. Bras. Enf.; DF, 31 : 478-495, 1978.

culos das regiōes ventro-glútea (local de Hochstetter) e face ântero lateral da coxa, como sendo os mais apropriados por apresentarem menor possibilidade de acidentes para 0 paciente.

Assim, Horta \& Teixeira (8), em 1973, apresentam a tabela (anexo I), indicando a prioridade dos locais para injeção I.M. conforme o grupo etário.

Castellanos (3) em 1977, indica como primeiro músculo a ser utilizado, o ventro-glúteo (local de Hochstetter) para "qualquer idade, especialmente para crianças e clientes magros, idosos ou edemaciados", não apontando nenhuma contra-indicação quanto a este local.

Castellanos (4) em outro trabalho também publicado em 1977, apresenta, como se vê no Anexo II, as indicaçōes dos locais para a injeção I.M., segundo o grupo etário, decúbito, cuidados especiais e contra-indicaçōes.

Todos os autores são unânimes, quando afirmam ser o músculo deltóide o menos indicado para a aplicação da injeção I.M., seguido da região dorso-glútea.

Para o presente estudo considerou-se a prioridade das regiōes de aplicação da injeção I.M. na seguinte ordem: ventro-glútea (local de Hochstetter), face ântero lateral da coxa, dorso-glútea $\mathrm{e}$ deltóide.

Vários autores consideram que a técnica da injeção I.M. envolve, por parte do profissional que a executa, além da destreza e habilidade manual, conhecimentos de anatomia, farmacologia, domínio das medidas de assepsia médica (A.M.) e assepsia cirúrgica(A.C.) referentes à mesma e, ainda, as regras básicas da comunicação com o paciente.

A ausência de habilidades técnicas e/ ou conhecimentos científicos, podem ocasionar sérios problemas ao paciente como a não aceitação do tratamento por falta de preparo psicológico, acidentes gerais graves como: infecçōes, fenômenos alér- gicos, má absorção da droga, embolias, traumas quer de ordem psicológica como de tecido e, ainda, os acidentes especificos de cada local de aplicação de injeção I.M.

Os profisisonais da equipe de enfermagem devem receber durante o curso de formação e ou em cursos de atualização o preparo para que sejam capazes de efetuar o controle e a profilaxia dos problemas e acidentes.

A experiência vem demonstrando que este preparo tem sido insuficiente qualitativa e quantitativamente, o que repercute de forma negativa na qualidade da assistência prestada ao paciente.

Ciari (5) sugere o rendimento instrumental como um dos indicadores da avaliação quantitativa de assistência prestada.

A determinação do rendimento instrumental de cada técnica favoreceria a racionalização do trabalho da equipe de enfermagem.

Assim, por exemplo, sabendo-se que para ministrar medicamentos por via I.M. são necessários " $X$ " minutos, podese prever e planejar cientificamente os recursos humanos e materiais indispensáveis, advindo o aumento de produtividade e melhoria da assistência prestada ao paciente.

\section{II - OBJETIVOS}

Desconrecendo-se a existência de estudos relacionados com o rendimento instrumental da maioria das técnicas de Enfermagem, realizou-se o presente trabalho, no qual foram estabelecidos os seguintes objetivos:

1. Determinar o rendimento instrumental da ministração de medicamentos por via intramuscular em pacientes hospitalizados.

2. Medir: - o grau de exatidão da técnica da injeção I.M. 
HORR, L. e colaboradoras - Determinação do rendimento instrumental da ministração de medicamentos por via intramuscular em paciente hospitalizados. Rev. Bras. Ene.; DF, 31 : 478-495, 1978.

- o grau da aplicação de conhecimentos científicos relacionados à técnica da injeção I.M., realizada pelos Auxiliares de Enfermagem.

- a observância do horário na ministração de medicamentos por via intramuscular.

3. Identificar: os locais mais utilizados na ministração da injeção I.M., comparando-os com os locais indicados cientificamente.

- a previsão e provisão de medicamentos ministrados por via I.M.

\section{III - METODOLOGIA}

\section{População}

No presente estudo inclusive a observação de todas as injeçōes I.M. aplicadas em pacientes previdenciários internados nas unidades médicas e cirúrgicas durante um periodo de quinze dias.

Adotou-se para determinar a referida população, os seguintes critérios:

- Hospital Geral.

Optou-se por esta entidade assistencial, por ter um Serviço de Enfermagem estruturado, onde atua o maior número de enfermeiros do Estado, 13 (treze) enfermeiros.

Este nosocômio serve também de campo de estágio às alunas do Curso de Graduação e pós-Graduação em Enfermagem.

Além de contar com um serviço de Pronto Atendimento, Centro de Terapia Intensiva, possui seis Unidades de internação, perfazendo um total de 231 leitos.

\section{- Unidades de Internação.}

Através de um levantamento prévio durante cinco dias nas seis Unidades de Internação, obteve-se um total de 133 (cento e trinta e três), injeções nas vinte e quatro horas, assim distribuidas: clínica cirúrgica masculina: 36 ; clínica cirúrgia feminina: 34 ; clínica médica feminina: 28; clínica médica masculina: 23; clínica médico-cirúrgica masculina: 9 e clínica médico-cirúrgica femínina: 3.

As unidades de Internação que apresentaram um número médio inferior a vinte injeções nas vinte e quatro horas, foram excluídas da pesquisa para facilitar a efetivação do estudo em menor tempo. Assim, as Unidades de Clínicas Médicas e Cirúrgicas masculinas e femininas foram incluídas no presente trabalho.

- Executores da técnica da injeção I.M.

O elemento observado $n$ a técnica da injeção intra-muscular foi o Auxiliar de Enfermagem, cuja principal atividade diária neste hospital é a ministração de medicamentos. Foram, portanto, excluidos os Técnicos de Enfermagem e Atendentes que também executam a mesma atividade.

A observação da Técnica de injeção I.M. realizou-se nos três turnos (manhã, tarde e noite) de funcionamento das Unidades de Internação estabelecidas acima, onde os Auxiliares de Enfermagem que desempenhavam atividades quando do momento do estudo, passaram a ser observadös.

- Injeção intramuscular.

Querendo-se determinar o rendimento instrumental de uma técnica de enfermagem, elaborou-se uma listagem das mais freqüentes do dia a dia e optou-se, aleatoriamente, pela técnica da injeçāo intramuscular.

Fizeram parte da amostra as injeçōes preparadas e aplicadas uma a uma e as preparadas e aplicadas em série.

- Tempo

Para determinar o tempo gasto na ministração de medicamentos por via 
HORR, L. e colaboradoras - Determinaçăo do rendimento instrumental da ministraçåo de medicamentos por via intramuscular em paciente hospitalizados. Rev. Bras. Enf.; DF, 31 : 478-495, 1978.

I.M., usou-se a cronometragem por ser o meio mais simples e mais conhecido para o estudo do tempo.

A cronometragem foi "contínua", isto é, o ponteiro, partindo sempre de zero, não foi parado depois de posto em movimento, a não ser em intercorrências alheias à técnica e novamente acionados quando do reinício da atividade em estudo.

Nas injeçōes I.M. preparadas e aplicadas em série, o tempo foi computado em conjunto, isto é: os procedimentos da técnica que se repetiam durante 0 preparo e aplicação de cada injeção, foram registrados uma só vez. Ex.: limpeza da bandeza, limpeza do local após o preparo.

\section{Amostragem}

A amostragem foi calculada na variável "Tempo", operacionalmente necessária para a apliação de uma injeção I.M., onde o desvio padrão, foi fixado aleatoriamente em 2 (dois) minutos, em nível de confiança de $95 \%$. Aplicada a fórmula do "n mínimo corrigido", porquanto a população é finita, tem-se: $\mathrm{n} \geqslant$ 180,93 ou seja 181.

Onde, $\mathbf{Z C}=$ área subentendida pela curva normal reduzida; $\mathbf{S}=$ Desvio padrão; $\mathbf{N}=n .^{\circ}$ de passos; e $=$ epm.

A fórmula "n mínimo" normalmente é aplicada para população finita, onde, por correspondência, o universo é conhecido.

Entretanto, ao se relacionar com o tempo e conhecimento o segmento do percurso procede-se sua correção elevando o " $n$ " ao quadrado e retirando-o do divisor.

\section{Instrumento.}

Escolheu-se como meio de coleta de dados o formulário. Foram elaborados em número de quatro.
Um deles refere-se a observação da técnica da injeção I.M. que, após ser testado, sofreu as devidas alteraçōes. Os demais, reportam-se, respectivamente, à entrevista com os Enfermeiros Chefes das Unidades de Internação selecionadas, com os Auxiliares de Enfermagem observados na execução da técnica e com os pacientes que receberam medicamentos por via I.M. durante o período de observação da técnica.

\section{Pré-Teste.}

Com a finalidade de testar o formulário referente a observação da técnica da injeção I.M. e de calibrar os pesquizadores, realizou-se o pré-teste. Constou de 22 (vinte e duas) injeçōes I.M. observadas, nas Unidades de Internação estabelecidas para o trabalho.

Calibrados os pesquisadores, o instrumento, sofreu as modificaçōes necessárias sentidas depois de testado, analisado e avaliado.

\section{Coleta de dados.}

Efetuou-se a coleta de dados através de:

5.1. Observação direta da execução da técnica da injeção I.M., conforme formulário padrão, fundamentado em Horta \& Teixeira (8), elaborado especificamente para o estudo, a fim de estabelecer perâmetros nos seguintes aspectos da técnica de aplicação de in jeção I.M.: assepsia médica; assepsia cirúrgica; princípios teórico-científicos; locais de aplicação; tempo gasto na execução.

5.2. Entrevista formal com: os Auxiliares de Enfermagem componentes do estudo; os pacientes nos quais foram $\mathrm{mi}$ nistrados medicamentos por via I.M., e que apresentavam condiçōes para serer entrevistados; os Enfermeiros Chefes das 
HORR, L. e colaboradoras - Determinaçáo do rendimento instrumental da ministraçáo de medicamentos por via intramuscular em paciente hospitalizados. Rev. Bras. Enf.; DF, 31 : 478-495, 1978.

Unidades de Internação envolvidas pela pesquisa.

\section{Tratamento dos dados.}

Visando descrever dados obtidos na amostra estudada e avaliar a precisão das generalizaçōes para a população total, usou-se:

- Média, uma das medidas de tendência central representativa de um conjunto de dados para caracterizar o que é típico no grupo.

- Percentagem, para indicar a freqüência relativa.

- Desvio padrão, indicando até que ponto variam os individuos do grupo.

- Curva normal, para mostrar a maneira pela qual os indivíduos se distribuem em relação à variável que está sendo medida.

- Relação, como comparação entre duas variáveis.

- Correlação explicando a relação entre as variáveis.

- Significância, como probabilidade ou grau com o qual se sujeitaria a correr o risco de um erro.

- Grau de serviço para determinar a relação entre a média especifica e a quantidade amostrada.

- Acessibilidade como designação de acesso a cada etapa consecutiva dentro de uma determinada técnica.

Para determinar o nível de conhecimento do Auxiliar de Enfermagem quanto ao tipo de medicamentos por ele ministrado, utilizou-se a seguinte classificação:

Nivel 1 - Insuficiente: $00 \%$ a $49,99 \%$

Nível 2 - Regular: $\quad 50 \%$ a $62,99 \%$

Nível 3 - Bom: $\quad 63 \%$ a $75,99 \%$

Nível 4 - Muito bom: $76 \%$ a $88,99 \%$

Nível 5 - Ótimo:

$89 \%$ a $100,00 \%$

\section{IV - RESULTADO E DISCUSSAO}

Os resultados obtidos pela observação dos 46 (quarenta e seis) passos da técnica da injeção I.M. permitiram observar que os princípios científicos relacionados à técnica da injeção I.M. alcançaram $89,84 \%$ de desempenho positivo.

Em relação à assepsia médica, o re-

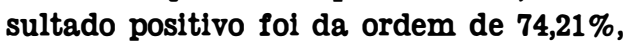
enquanto que a assepsia cirúrgica atingiu $99,66 \%$.

No procedimento "lavou as mãos", o percentual $72,93 \%$ positivo, que pode parecer animador à primeira vista, decresce, considerando-se que o mesmo se refere somente à lavagem das mãos no início do preparo das injeçōes I.M. observadas. Os executores da técnica não lavaram as mãos na ministração das injeçōes I.M. entre um paciente e outro, quando estas foram preparadas 0 aplicadas em série, baixando, portanto, o percentual a 44,20.

Em função deste dado, o percentual 74,21 atribuido à assepsia médica, baixa para $69,42 \%$.

Está provado que a lavagem das mãos é um principio de assepsia médica indispensável para prevenir a infecção cruzada. Ramos (15) comenta a este respeito: "Sabe-se pelos estudos mais recentes, que a maioria das infecçōes hospitalares é transmitida por contacto direto das mãos, sendo esta a via de infecção mais importante, tanto à domicílio como na área hospitalar, onde a variedade de cepas de microorganismos é maior".

O tempo gasto para execução da técnica diminui quando da administração em série, entretanto, a qualidade do seu desempenho baixa, o que pode comprometer a eficácia da técnica e colocar em risco a segurança do paciente.

Outros fatores que poderiam implicar na segurança do paciente se referiram 
HORR, L. e colaboradoras - Determinaça do rendimento instrumental da ministraçæo de medicamentos por via intramuscular em paciente hospitalizados. Rev. Bras. Enf.; DF, 31 : 478-495, 1978.

a não correta observância de procedimentos da assepsia médica como: antissepsia dos frascos-ampola feita diretamente na cuba com algodão, álcool e tesoura estéril, empregada normalmente para cortar a ponta dos soros com embalagem plástica, fol usada para retirada da tampa metálica dos frascosampola.

No procedimento "selecionou seringas e agulhas", verificou-se preocupação por parte do aplicador, porém, o material a sua disposição apresentava deficiências, interferindo no tempo"gasto para a aplicação das injeções, a saber: êmbolo lnadequado ao corpo da seringa; agulhas entupidas; bizéis rombos; comprimento e calibre das agulhas não condizentes com o medicamento a ser ministrado e com a espessura da tela sub-cutânea do paciente, o que contraria a indicação de Horta \& Teixeira (8).

Por outro lado, constatou-se falta de cuidado no manuseio do material a exemplo de "agulhas Jogadas à dístância sobre o balcão, danificando-as, o que aumenta a probabilidade de traumatismo tíssular nas próximas aplicações, caso nāo haja um bom serviço de preparo de material e pode influir na economia hospitalar.

No procedimento "verificou as condições dos músculos", a maioria dos aplicadores, $\mathbf{7 7 , 3 5 \%}$ positivos demonstraram esta preocupação, sem contudo seguirem um rodlzio programado, continuando a aplicar injeçōes em áreas musculares que se apresentavam edemaciadas, endurecidas, hiperemiadas e com visivel concentração de picadas de agulha.

O procedimento "ministrou a dose certa", atingiu $85,08 \%$ positivos, observando-se, contudo, uma intercorrência significativa: medicamentos liofilizados, cujo conteúdo não era utilizado de uma só vez, o que restava no frasco não recebia a devida identificação. Isto poderá causar dúvidas quanto à dosagens nas aplicaçōes seguintes, colocando em risco o paciente, por ministração de doses excessivas ou incompletas.

No procedimento "ministrou na hora certa", o percentral 6,63 negativos refere-se a problemas de ordem administrativa ou seja: o horário previsto para o descanso de alguns dos Auxdliares de Enfermagem observados, colncida com o horário estabelecido para medicamentos. Ex.: medicaçāo programada para 12 horas fol ministrada entre 11 e 11,30 horas.

Em se tratando de antibióticos, cujo horário deve ser cumprido rigorosamente, a não observância do mesmo favorece a afirmação de Sabath citado por GOODMAN (6) quando diz que "doses subbttmas" são causa de resistência dos germes ao tratamento.

Ainda sobre medicamentos, chamou a atenção dos pesquisadores: - falta de boa distribuição horária nas 24 horas do dia, principalmente nos horários noturnos, podendo interferir no repouso dos pacientes; - medicamentos prescritos, inclusive antibióticos, não ministrados, por estarem em falta na farmácia.

Das medicações ministradas, no que tange ao procedimento "encontrou a medicação na gaveta do paciente", o mesmo alcançou $98,34 \%$ positivos, nāo estando, portanto, incluídos os medicamentos em falta na farmácia, que pela inexistência na Unidade de Internação, não foram aplicados e consequentemente não observados.

O procedimento "explicou ao paciente o que ia fazer", atingiu um percentual positivo elevado de 93,37 , porém, os apilcadores limitavam-se a dizer ao paciente: "Vamos tomar uma injeçãozinha?", "Onde o Sr.(a) quer que aplique?". Tal ocorrência parece demonstrar que a escolha do local da injeção I.M. fica só a critério do paciente. Ressente-se da falta de orientação e esclarecimento quanto a existência e vantagens da utilização dos diversos músculos. 
HORR, L. e colaboradoras - Determinaçāo do rendimento instrumental da ministraçāo de medicamentos por via intramuscular em paciente hospitalizados. Rev. Bras. Enf.; DF, 31 : 478-495, 1978.

No que se refere ao "local de aplicação" $65,19 \%$ positivos atribuem-se a região do deltóide, $23,76 \%$ ao dorso-glútec, $11,04 \%$ face ântero-lateral da coxa e nenhuma à região ventro-glútea.

Comparando-se os músculos utiüźados com os cientificamente indicados, notase uma inversão no uso dos mesmos.

Autores citados por Castellanos (4) especificam as contra-indicaçōes e os acidentes que podem ocorrer segundo a região.

- Com referência à região deltóide: Horn ' recomenda esta região como última alternativa para soluçōes pouco irritantes e doses não superiores a $1 \mathrm{ml}$. Cita o problema de ser uma área bastante dolorosa e o perigo de se atingir a artéria umeral e o nervo radial".

Hanson "opina que esta região deve ser evitada, a não ser quando se usarem substâncias não irritantes, pois a massa muscular é pequena e injeçōes mal localizadas podem envolver o nervo radial com dor, sensibilidade maior nesta área e neuropatia paralisante".

Rauch "indica a utilização desta região unicamente para o caso de inoculações em massa e em pacientes com extensas queimaduras".

Horta \& Teixeira "fazem referência a pequena massa muscular desta região que não permite sejam injetadas mais que $4 \mathrm{ml}$ de solução, não podendo por isto ser utilizada para grande número de aplicaçōes consecutivas. Citam a possibilidade de lesão tissular de ramos do feixe vásculo-nervoso em caso de variaçōes anatômicas individuais e também por aplicação fora da área e mencionam lesão do nervo radial se a injeção for aplicada na face póstero-lateral do braço ou na borda inferior do deltóide. As lesōes são graves podendo levar à paralisia dos mais importantes músculos do braço e antebraço".

- Com referência a região dorsoglútea: Vários autores a indicam "desde que se tomem certas precauçōes devido ao perigo de se lesar o nervo ciático" e outros a "contra-indicam para crianças menores de 2 anos, pois nesta faixa etária a região é composta primariamente de tecido adiposo e há somente um pequeno volume de massa muscular, o qūal se desenvolve, posteriormente, com a locomoção, podendo por isso ser usado quando a criança já anda há um ano ou mais, geralmente na idade de 2 a 3 anos".

Hochstetter aponta como complicaçōes menos freqüentes: 'embolias arteriais e venosas, tromboses, lesōes do nervo glúteo caudal, do nervo glúteo cranial e do nervo cutâneo femural dorsal e hematomas".

Podem ainda ser referidas: - as variaçōes na expessura da tela subcutânea, dificultando o acesso à profundidade da massa muscular; - intensa vascularização e inervação da região.

- Com referência a face ântero-lateral da coxa: A região da face ânterolateral da coxa é considerada por vários autores "como sendo uma área livre de vasos e nervos importantes e de fácil acesso, tanto para o profissional, como o próprio paciente que dela poderá utilizar-se sozinho".

Horta \& Teixeira "mencionam que pode haver lesão acidental do nervo femural cutâneo, que percorre a tela subcutânea, com inúmeros filetes que inervam toda a face lateral da coxa, com distúrbios sensorais, causando dor momentânea, razão pela qual muitos clientes recusam injeçōes neste local".

Alguns autores contra-indicam esta região para recém-nascidos pela possibilidade de provocar contratura do quadriceps femural.

- Com referência a região ventroglútea: Hochstetter, após ampla investigação, afirma "ser essa região mais indicada por estar livre de estruturas importantes', não havendo "nervos ou va- 
HORR, L. e colaboradoras - Determinaçáo do rendimento instrumental da ministraçáo de medicamentos por via intramuscular em paciente hospitalizados. Rev. Bras. Enf.; DF, $31: 478-495,1978$.

sos significantes, pois a área é servida por múltiplos pequenos nervos e ramificaçōes vasculares; na profundidade está selada por osso, das estruturas vitais aí situadas. A direção dos feixes musculares é tal que previne o deslisamento do material injetado em direção ao nervo ciático".

A condição de validade da técnica de ministrar medicamentos por via intramuscular, medida pelas variáveis tempo, número de injeçōes passos da técnica e entrevista é que as "şaídas" - injeçōes aplicadas - sejam feitas obedecendo a cada fonte dos passos (quarenta e seis) da técnica o que denominamos "entrada" - preparação das injeçōes.

Alguns passos da técnica e entrevista não foram satisfatórios à esta condição de "entrada" e "saída".

Um grupo de 181 (cento e oitenta e uma) injeçōes I.M. com acessibilidade completa a todas as "entradas" tiveram a capacidade de acerto de $79,63 \%$, com um grau de serviço "sim", Ps $=0,44 \%$ $\left(P s=\mathrm{X}_{\mathrm{B}} \% \div 181\right)$. Isto demonstra que a técnica da injeção I.M. está $15,37 \%$ abaixo do padrão considerado ótimo, porquanto, fixou-se o limite de aceitação em 95\%, admitindo-se um erro máximo de $5 \%$.

Se, entretanto, as 181 injeçōes I.M., forem divididas em quatro segmentos quanto aos passos ("sim", "não", "informação não disponível" e "não se aplica") e cada segmento de 46 (quarenta e seis) passos for separadamente acessível, em teoria, por $23,76 \%$ das "entradas" $(95: 4=23,76 \%)$., a quantidade de serviço, mostra-se altamente satisfatória, pois $95 \%-(79,63 \%+062 \%+7,85 \%)=$ $6,90 \%<15,37 \%$.

Esta teorização legitima-se, pois o ingresso dos valores "informação não disponivel" e "não se aplica", poderão probalisticamente estar inserido no "sim".
O valor médio da curva "não" é de $11,92 \%$ com acessibilidade completa a todas as "entradas" (46 passos da técnica), tem um grau de serviço "não", num grupo de 181 injeçōes I.M., Pn = $0.07 \%\left(x_{n}: 181\right)$. Isto demonstra que a técnica de aplicação de injeções I.M., está $6,92 \%(11,92 \%-5 \%)$ acima do padrão considerado ótímo, porquanto encontra-se fora do limite de rejeição máxima que foi fixado em $5 \%$.

Admitindo-se o mesmo raciocínio de segmentar os passos quanto ao tipo de observaçōes ("sim", "não", "informação não disponível" e "não se aplica") e cada segmento de 46 passos for separadamente acessivel, teoricamente, por uma rejeição de $1,25 \%(5 \% \div 4)$ das "entradas", a qualidade dos serviços, mostra-se altamente satisfatória.

$5 \%-(11,92 \%+0,62 \%+7,85 \%)=$ $-15,37 \%<6,90 \%$.

Volta-se a legitimar a teorização, pois, a "informação não disponível" e "não se "aplica", podem probabilisticamente estar inseridas no "não".

Esta análise vem permitir a aceitação da divisão feita ("sim" "não", "informação não disponível" e "não se aplica") na significância de $95 \%$.

Este método de agrupamento pode-se denominar de gradação ou agrupamento de passos, dentro de uma técnica definida, onde:

grau de serviço "sim" $=P s=0,44 \%$ grau de serviço "não" $=\mathrm{Pn}=0,07 \%$

A acessibilidade é, contudo, limitada em muitos casos na técnica de injeção I.M., isto é, a quantidade de passos necessários a sua plena consecução, sofre na medida que aumenta, teoricamente, uma diminuição no grau de serviço em que passa a se chamar como "símbolo de acessibilidade" e designar por $\mathbf{K}$. Assim, a acessibilidade limitada por $\mathbf{K}$, poderia, sem perder sua significância de $95 \%$, ser aumentada somente em $6,29 \%$ $(0,44 \%: 0,07 \%)$ de passos ou seja 6 
HORR, L. e colaboradoras - Determinação do rendimento instrumental da ministraçāo de medicamentos por via intramuscular em paciente hospitalizados. Rev. Bras. Enf.; DF, 31 : 478-495, 1978.

passos, por se tratar de uma variável discreta.

Os diferentes passos da técnica empregam diferentes seletores nos estágios consecutivos, dispostos numa certa ordem e/ou preferência. O caso do local onde se aplicou a injeção I.M. é um exemplo expressivo. A ordem e/ou a preferência poderia ser no deltóide, dorsoglúteo, vasto lateral ou ventro-glúteo, agrupados em quatro passos, os quais, efetivamente, diminuem a média do segmento considerado, diminuindo, por conseguinte, o grau de serviço e a cessibilidade.

Os dados extraídos e equacionados são:

$$
\mathbf{x}(181)=\underset{\text { cadas }}{\text { a quantiade de injeçōes apli- }}
$$

y (46) = os passos da técnica

Ps $(0,44 \%)=$ grau de serviço "sim"

$\mathbf{K}$ (6) = acessibilidade complementar

$\mathrm{Na}$ relação entre os diversos estágios sucessivos da técnica com a operação do Auxiliar de Enfermagem, denominada "operação I.M.", pode-se, além dos passos da técnica, relacionar o "tempo".

O tempo médio necessário para ministrar uma injeção I.M., no presente estudo foi de 4,56 min (quatro minutos e cincoenta e seis segundos) com um desvio padrão de $1,15 \mathrm{~min}$ (um minuto $e$ quinze segundos), o que permite concluir ser razoável em termos de produtividade marginal, ao atingir o tempo $(x-d p)$ $3,41 \mathrm{~min}$ (três minutos e quarenta e um segundos), obedecidos os parâmetros disponíveis. O tempo decresce na razão direta da quantidade de injeçōes I.M. aplicadas, embora não se distanciando muito da média e do seu respectivo desvio-padrão somado, para se fixar em base constante de $4,30 \mathrm{~min}$ (quatro minutos e trinta segundos). O decréscimo é sentido quando se observa o desvio-padrão que varia em 2,1 min (dois minutos e um segundo) para 32 seg (trinta e dois segundos) na aplicação de uma para cinco injeções I.M. aplicadas, respectivamente.

Embora na aplicação de quatro injeçōes I.M. o tempo médio e o desviopadrão aumentem em 20 seg. (vinte segundos) e $21 \mathrm{seg}$ (vinte e um segundos), na análise dessa variância, os dados não se tornam significativos, a ponto de merecer um re-estudo, porquanto a tendência orienta que essa divergência é devida a fatos aleatórios momentâneos ocorridos no curso da aplicação (Análise igual a 0,08).

Na relação "tempo" ocorrem, porém, divergências quando o quantitativo supera 6 (seis) injeçōes I.M., pois em 7 (sete) a média sobe a $5,35 \mathrm{~min}$ (cinco minutos e trinta e cinco segundos), o que daria, numa projeção teórica, um acréscimo bastante expressivo. Assim, aleatoriamente, se fixaria, para cada "módulo" (número de injeçōes I.M. que um Auxiliar de Enfermagem aplica cada vez que se desloca com essa finalidade operativa), a aplicação de 6 (seis) injeçōes I.M.

Os resultados obtidos através das entrevistas realizadas com Enfermeiros, Auxiliares de Enfermagem e pacientes foram:

Dos 4 cnfermeiros das Unidades de Internação entrevistados, $100 \%$ tomaram conhecimento de alguma publicação recente sobre I.M., sendo que o fizeram através das seguintes fontes: curso de graduação e estudo individual $25 \%$; estudo individual $25 \%$; outros colegas $25 \%$ e curso de graduação $25 \%$. Assim, como fonte para obtenção do conhecimento acerca da injeção I.M., apresentou-se como moda: o "Curso de Graduação" e "estudo individual".

Como referência bibliográfica sobre a injeção I.M. os enfermeiros citaram: 25\% Horta \& Teixeira (8); 25\% Kozier \& DuGas (9), e 50\% Kozier \& Dugas (9) . 
HORR, L. e colaboradoras - Determinação do rendimento instrumental da ministraçăo de medicamentos por via intramuscular em paciente hospitalizados. Rev. Bras. Enf.; DF, 31 : 478-495, 1978.

Em relação a pergunta "você orienta os funcionários sobre a ministração de medicamentos por via I.M., $100 \%$ dos enfermeiros afirmam orientar os funcionários ocasionalmente e destes, $50 \%$ também o fazem em reuniōes técnicas que realizam e nenhum 0 faz diariamente.

As "condições dos músculos" dos pacientes são observadas "periodicamente" por $\mathbf{7 5 \%}$ dos Enfermeiros e $25 \%$ "diariamente".

A "orientação e supervisão do rodízio dos músculos" é feita periodicamente por 25\% dos Enfermeiros; $50 \%$ nunca o fazem e $25 \%$ utilizam reuniōes para tal orientação.

Sabe-se que o não rodízio dos músculos na ministração de medicamentos inJetáveis por esta via podem determinar sérias complicações ao paciente e preJudicar o tratamento como refere Horta \& Teixeira (8) "má absorção das drogas", "fenômeno de Arthus", dor local, desconforto ao paciente e recusa ao tratamento.

A orientação do paciente quanto ao local de aplicação da injeção I.M., é feita por 50\% dos Enfermeiros; $25 \%$ não o fazem e $25 \%$ a praticam às vezes.

Analisando simultaneamente as variáveis "orienta o funcionário sobre a ministração de medicamentos por via I.M., "observa as condições dos músculos dos pacientes" e "orienta e supervisiona o rodízio dos músculos", observa-se: não há medidas diárias nestas determinantes; há uma única relação significativa, $75 \%$, entre elas quanto ao procedimento 'periódico". Existe, ainda, uma relação média inferior em $38 \%$ dos Enfermeiros que "nunca" e/ou "em reunião" orientam os funcionários, observam e supervisionam as condiçōes dos músculos dos pacientes.

Embora o Enfermeiro tenha conhecimento de publicaçōes recentes sobre injeçōes I.M., a orientação ao paciente encontra uma significância racional mé- dia, pois somente $50 \%$ o fazem, segundo seu próprio testemunho. Correlacionando estes dados pela rejeição às respostas dos pacientes, nota-se que esta orientação não é dada ou seja a confiabilidade desce a 0,003 e, efetivamente, a mesma inexiste.

Dos dezenove Auxiliares de Enfermagem que executaram a técnica de injeção I. M., $26 \%$ participaram de curso de atualização no perlodo de julho de 1976 a Julho de 1977, onde fol abordado o assunto injeção I.M. e os demais, $74 \%$ não participaram.

O músculo "mais usado" pelos Auxiliares de Enfermagem na aplicação da inJeção I.M. fol o deltóide, atingindo $63 \%$ seguido do dorso-glúteo com $26 \%$ e vastolateral da coxa com $11 \%$. O ventro-glateo (Hochstetter) não fol utilizado dentro da amostra. Estes músculos, segundo as respostas dos Auxiliares de Enfermagem, são mais usados porque em $32 \%$ "o paciente recusa os demais músculos" e por "ser de maís fácil acesso"; $26 \%$ porque é "menos perigoso" quanto a acidentes; $5 \%$ porque "dói menos" e porque "desconhecem os outros locais".

Os Auxiliares de Enfermagem consideram a injeção I.M. "uma técnica simples, fácil e de pouca importância" em $5 \%$ enquanto que $95 \%$ a reputam como "complexa, diflcil e importante, dado coincidente com a afirmação de Horta \& Teixeira (8) "além dos conhecimentos de farmacologia e habilidade na técnica, é indispensável que o profisisonal esteja consciente e seguro das medidas de assepsia médica e cirúrgica aplicáveis ao caso".

Quanto a orientação dada ao paciente pelos Auxiliares de Enfermagem sobre a aplicação da injeção I.M., $63 \%$ a reallzam; $11 \%$ não e $26 \%$ ocasionalmente.

Por sua vez, nenhum Auxiliar de Enfermagem recebe orientação diária do Enfermeiro Chefe da Unidade de Inter- 
HORR, L. e colaboradoras - Determinação do rendimento instrumental da ministração de medicamentos por via intramuscular em paciente hospitalizados. Rev. Bras. Enf.; DF, $31: 478-495$, 1978.

nação sobre a aplicação da injeção I.M.; $11 \%$ a recebem periodicamente, $5 \%$ em reuniōes e $84 \%$ informam nunca receberem orientação.

Relacionando as informaçōes "orienta o funcionário sobre a ministração de medicamentos por via I.M." e "você recebe orientação do Enfermeiro sobre a aplicação de injeção I.M.", constatase que $100 \%$ dos enfermeiros informam dar orientação aos funcionários, enquanto que $84 \%$ destes afirmam nunca a terem recebido. Inferindo estatisticamente, o nível de confiabilidade, sobre estas duas informaçōes, desce a $12 \%$.

Em resposta à pergunta "qual o tipo de medicamento por você ministrado?", constatou-se que $83,84 \%$ dos Auxiliares de Enfermagem conheciam o medicamento, o que os enquadra no Nível 4 Muito bom - da classificação estabelecida pelos pesquisadores, enquanto que 9,09\% apresentaram conhecimento errado e $7,07 \%$ desconheciam a medicação que ministraram.

Salienta-se que a obtenção do alto percentual positivo foi favorecido pelo fato de ter sido apenas perguntado o tipo de medicamento e não a ação e os efeitos do mesmo. Mesmo assim, tratando-se de ministração de medicamentos efetuados por profissionais, esperava-se um conhecimento ótimo.

Dos pacientes que receberam medicamentos por via I.M. durante o período de observação da técnica, $83 \%$ apresentaram condiçōes para serem entrevistados. Deste, $97 \%$ informaram não terem sido orientados neste Hospital quanto à aplicação de injeção I.M., e 3\% responderam afirmativamente.

Os enfermeiros informaram em $50 \%$. orientar os pacientes quanto ao local da injeção I.M. e $89 \%$ dos Auxiliares de Enfermagem também o fazem.

Assim, o nível de confiabilidade da informação sobe a $99 \%$, com uma rejei- ção diminuta de 1\%. Tal informação, todavia, não é confirmada pelos pacientes que em $97 \%$ informaram não terem sido orientados quanto ao local da aplicação da injeção I.M. Relacionando sucessiva, mas interligadamente a informação, observa-se que a signifícância desce à confiabilidade de $29 \%$.

Os pacientes, $94 \%$, revelaram receber a injeção I.M. no deltóide e $6 \%$ no dorso-glúteo. Esta afirmativa encontra relação quase integral com a fornecida pelo Auxiliar de Enfermagem, dando 93\% de confiabilidade à informação.

A preferência dos pacientes quanto ao local de aplicação de medicamentos por via I.M. é de $88 \%$ no deltóide, $9 \%$ no dorso-glúteo e $3 \%$ no vasto-lateral. Esta opção, contudo, não é determinada por vontade expressiva dos mesmos, pois $59 \%$ "desconhecem os outros locais", $32 \%$ porque "dói menos", $6 \%$ porque "tem vergonha" e $3 \%$, porque "tem medo".

Considera-se a orientação uma das funçōes basicas do profisisonal de Enfermagem.

Horta (7) em sua metodologia do Processo de Enfermagem quando aborda o grau de dependência quanto à natureza, destaca a orientação como parte inerente da assistência de enfermagem ao paciente.

Alvares (1) afirma que "a orientação como função da enfermeira deve ocupar uma posição prioritária, pois ao lado de permitir um relacionamento mais profundo com o paciente, esclarece-o sobre seus problemas de saúde e capacita-o com seus próprios meios a alcançá-la.

A sistematização da orientação, que implica em um grupo de açōes previamente planejadas, cuidadosamente organizadas e estruturadas, racionaliza o trabalho da enfermeira, permitindo-lhe atuar com segurança, objetividade $e$ eficiência." 
HORR, L. e colaboradoras - Determinaçáo do rendimento instrumental da ministraçåo de medicamentos por via intramuscular em paciente hospitalizados. Rev. Bras. Enf.; DF, 31 : 478-495, 1978.

\section{$\mathrm{V}$ - CONCLUSOES}

Este trabalho sugere as seguintes conclusões:

1. A hipótese de que "o princípios cientificos não são devidamente observados na execução da técnica da injeção I.M.", é aceita no nível de significância 0,05 , conforme conclusão do primeiro postulado: o grau de serviço (Ps) está 3,5\% abaixo do limite ótimo em que deveria situar-se.

2. Os locais cientificamente indicados para a aplicação da injeção I.M., foram inversamente utilizados o que se verifica nos resultados: ventro-glúteo $0 \%$, face ântero lateral da coxa $11,04 \%$, dorso-glúteo $23,76 \%$ e deltóide $65,19 \%$, confirmando, portanto, a hipótese.

3. Não foi confirmada a hipótese de que o "tempo empregado para ministrar uma injeção I.M. aumenta na razão inversa dos locais menos indicados cientificamente", por não terem sido utillzadas todas as regiōes.

4. "A previsão e provisão dos medicamentos por via I.M. para cada paciente nas 24 horas" foram satisfatórias, $\mathbf{9 8 , 3 4 \% , ~ o ~ q u e ~ t a l v e z ~ t e n h a ~ i n t e r f e r i d o ~}$ no tempo médio encontrado $(4,56 \mathrm{~min})$.

5. Ao nível de significância 0,05 , rejeita-se a hipótese: "o tempo médio requerido para a aplicação de uma injeção I.M. varia de 6 a $10 \mathrm{~min}$ ", porquanto, o escore $\mathrm{z}$ da média amostral está fora do intervalo 1,96. Pelo mesmo raeiocínio rejeita-se a mesma em qualquer nivel, pois:

$$
\begin{aligned}
& \mathrm{z}=6-4,56=1,25 \cong 39,44 \% \\
& 1,15 \\
& \mathrm{z}=\frac{10-4,56=4,73>3,9 \cong>50,00 \%}{1,15}
\end{aligned}
$$

Porquanto a média é de $4,56 \mathrm{~min}$ e o desvio padrão de $1,15 \mathrm{~min}$.
6. Há pouca preocupação por parte do Enfermeiro em orientar e supervisionar funcionários e pacientes sobre injeção I.M.

7. Os Auxiliares de Enfermagem não orientam os pacientes quanto a existência e vantagens da utilização dos diversos músculos indicados para a injeção I.M.

8. A maioria dos pacientes desconhece as regiōes ventro-glútea e face ântero lateral da coxa, justamente as que oferecem maior segurança para a aplicação da injeção I.M.

9. O tempo médio gasto para preparar e aplicar uma injeção I.M. é maior do que quando as injeções são preparadas e aplicadas em série.

10. Os resultados relativos à execução da técnica da injeção I.M. alcançam um padrāo considerado Bom.

\section{VI - RECOMENDAÇOES}

1. Considerando que o procedimento da injeção I.M. envolve princípios de administração hospitalar, recomenda-se:

A administração do hospital, que:

- Crie condições e estimule a realização de cursos de atualização regulares para a equipe de enfermagem, tornando-a mais ficiente no desempenho de suas atividades junto ao paciente.

- Assessore-se de Enfermeiro na seleção e aquisição de material adequado para aplicação de injeções I.M.

- Procure prever e prover os medicamentos padronizados e necessários, evitando interrupções no tratamento do paciente.

2. Considerando que o referido hospital é campo de estágio para alunos de graduação e pós-graduação recomenda-se:

Ao Departamento de Enfermagem, que: 
HORR, L. e colaboradoras - Determinação do rendimento Instrumental da ministração de medicamentos por via intramuscular em paciente hospitalizados. Rev. Bras. Enf.; DF, $31: 478-495,1978$.

- Oriente e estimule os professores e alunos para que colaborem nos cursos de atualização da Equipe de Enfermagem nos diversos níveis.

- Esteja atento na formação dos alunos para os aspectos de ensino e orientação de funcionários e pacientes.

3. Considerando que a determinação do rendimento instrumental favorece a racionalização do trabalho da equipe de enfermagem e que a provisão e previsão de material adequado repercute positivamente no trabalho da mesma, recomenda-se:

A Chefia do Serviço de Enfermagem, que:

- Estimule e apoie os enfermeiros na realização de pesquisas para determinar o rendimento instrumental das técnicas de enfermagem, facilitando a previsão e planejamento de recursos humanos e materiais qualitativa e quantitativamente.

- Indique um enfermeiro para assessorar o Serviço de Material na aquisição de material utilizado pela enfermagem.

4. Considerando que o preparo adequado do material influi na eficiência e no tempo da execução de uma injeção I.M., recomenda-se:

A Chefia do Centro de Material que:

- Supervisione os funcionários no preparo e acondicionamento do material facilitando o desempenho das atividades de quem ministra a injeção I.M., evitando perda de tempo com substituição de material inadequado e garantindo a segurança do paciente.
5. Considerando que a orientação e os princípios de administração são funçōes inerentes do enfermeiro, recomenda-se:

Aos enfermeiros das Unidades de Internação, que:

- Supervisionem os funcionários na ministração de medicamentos por via I.M.

- Orientem os pacientes sobre a existência e vantagens da utilização dos diversos músculos.

- Verifiquem as condições dos músculos dos pacientes e orientem o rodízio dos mesmos.

- Colaborem na Educação em Serviço, incentivando $\mathrm{e}$ supervisionando os funcionários para que ponham em prática os conhecimentos adquiridos.

- Atentem para a distribuição horária das 24 horas, principalmente dos horários noturnos, para que o repouso dos pacientes seja assegurado e respeitado.

- Mantenham controle permanente sobre a qualidade e quantidade de material utilizado na injeção I.M.

6. Considerando que a execução da técnica da injeção I.M. envolve princípios científicos que garantem a segurança do paciente, recomenda-se:

Aos Auxiliares de Enfermagem que:

- Tenham interesse no seu próprio aperfeiçoamento técnico-científico.

- Participem ativamente nos programas de atualização que lhes são oferecidos.

- Apliquem devidamente os conhecimentos adquiridos, procurando, sempre que possível, utilizar os músculos, conforme indicação científica.

\section{VII - REFERENCIAS BIBLIOGRAFICAS}

01. ALVARES, L. H. A orientaçāo do paciente como funçāo da Enfermeira - Uma aplicaçāo em assistêncla de enfermagem cirúrgica. Monografia de mestrado. Esc. Enf. UFRJ, Rlo de Janeiro, 1975 p. 51.

02. CARDOSO, E. S. \& CAMARGO, T. A racionalização no Hospital. s. ed. Florlanópolis, s.Ed. 1977 p. 3. 
HORR, L. e colaboradoras - Determinaçăo do rendimento instrumental da ministraçăo de medicamentos por via intramuscutar em paciente hospitalizados. Rev. Bras. Enf.; DF, 31 : 478-495, 1978.

03. Casteulanos, B. E. P. Regiāo Ventro-Glutea: local seguro para aplicação de injeção por via intramuscular. Ene. Novas Dimens, 3(5) :289293, 1977.

04. Revisåo bibliográfica dos estudos relativos às diferentes regiōes para aplicação de injeção intramuscular. Rev. Esc. Enf. USP, 11 (2) :85-99, 1977.

05. CIARI JR. C. et alii. Avaliaçåo quantitativa de serviços pré-natal. Rev. Saúde Pública, São Paulo, 6, 361370, 1972.

06. GOODMAN, L. S. \& GILMAN, A. As bases farmacołogicas da terapéutica. 4. ed. Rio de Janeiro, Guanabara Koogan, 1973. p. 1068.

07. HORTA, W. A. O processo de Enfermagem - fundamentação e aplicaçảo. Enf. Novas Dimens., 1(1) :10-16, 1975.

08. HORTA, W. A. \& TELXEIRA, M. S. Injeçōes parenterais. Rev. Enf. USP, 7(1) :46-66, març., 1973.

09. KOZIER, B. B. \& DUGAS, B. W. Tratado de Enfermeria Prática. 2. ed. México, Interamericana, 1974. p. 251.

10. LEEDY, P. D. Practical research: planning and design. New York, Macmillan Publishing CO., Inc., 1974. p. 191-237.

11. LOPES, T. V. M. Problemas de pessoal da Empresa Moderna. 5. ed. Rio de
Janeiro, Fundação Getúlio Vargas, 1975. $317 \mathrm{p}$.

12. MARDONES, J. Farmacologia. 1. ed. Buenos Aires, Intermédica, 1976. p. 642-676.

13. NORDMARK. M. T. \& ROFWEDER, A. M. Princípios cientificos aplicados a la enfermeria. s. ed. México, Prensa Médica Mexicana. 1974 p. 3.

14. RAMOS, A. Procedimentos para Técntcos e Auxiliares de Enfermagem. 2. ed. Canadá, s. ed. 1977. p. 203.

15. RAMOS, L. M. F. M. B. et alli. Profilaxia e controle das infecços hospitalares na Unidade de Internaçio, pela higienizaçāo correta das máos. Enf. Novas Dimens., 2(1) :6-16, 1976.

16. SAUPE, R. et alli. Grau de conhecimento sobre nutriçāo infantil apresentado por mães de crianças que tiveram sarampo. Florianbpolis, s. ED. 1977. Mimeografado.

17. SCHOR, N. et alii. Diagnóstico da situação de assistência pré-natal em uma divisăo regional de saúde do Estado de Såo Paulo. 9, 351-362, 1975.

18. SELLTIZ, C. et alli. Métodos de pesquisa nas relaçōes sociais. Sāo Paulo, Pedag6 gica e Universidade Itda., 1975. p. 433-495.

19. SOUNIS, E. Bioestatística. e. ed. São Paulo, Mc Graw-Fill, 1972. 
HORR, L. e colaboradoras - Determinaçāo do rendimento instrumental da ministraçāo de medicamentos por via intramuscular em paciente hospitalizados. Rev. Bras. Enf.; DF, 31 : 478-495, 1978.

ANEXO I

TABELA 1 - PRIORIDADE DOS LOCAIS DE INJEÇAO POR GRUPO ETARIO

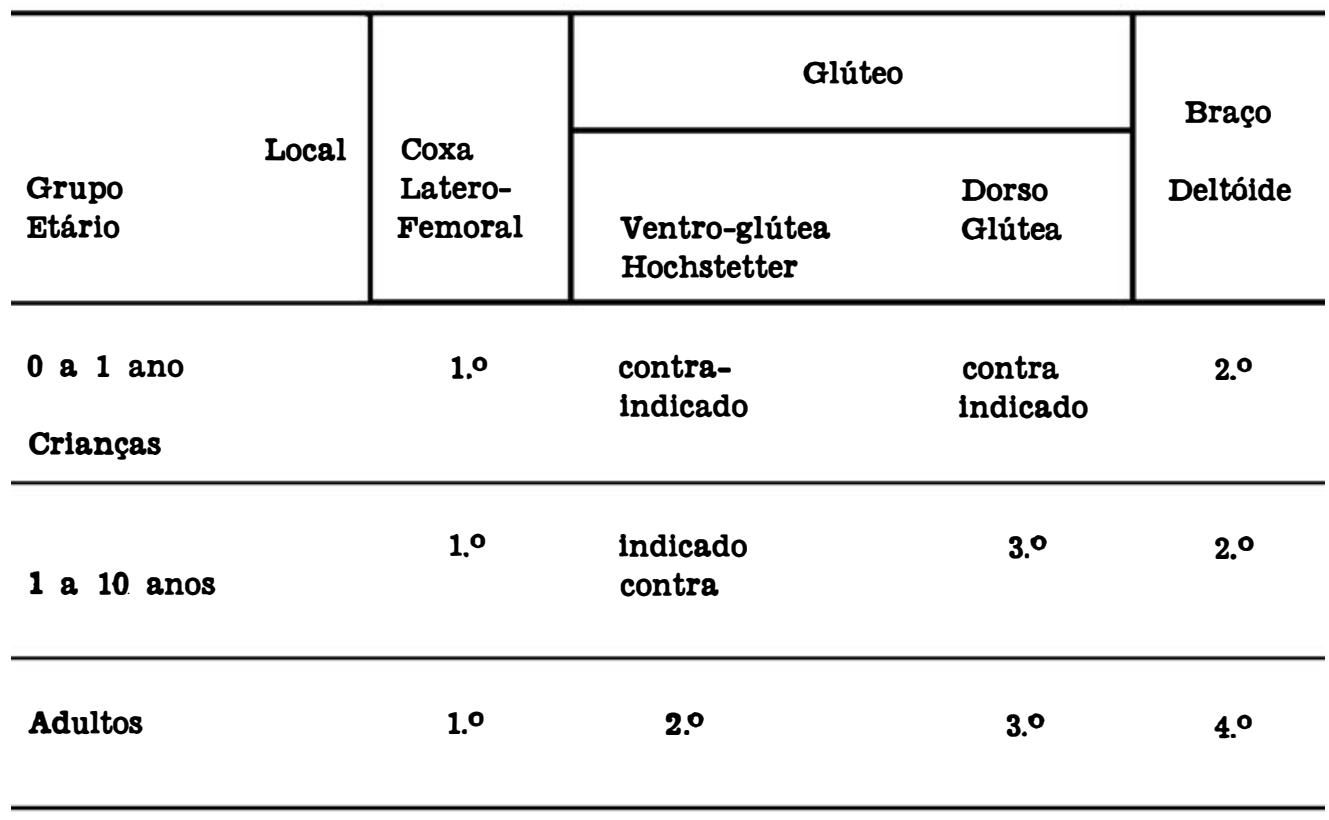

FONIE: HORTA, W. A \& TEIXEIRA, M. S. Injeções parenterais: Rev. Esc. Enf. USP, 7(1): p. 62, março, 1973. 
曰日

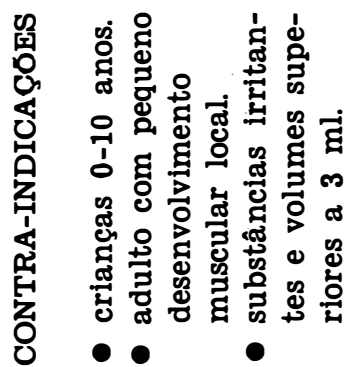

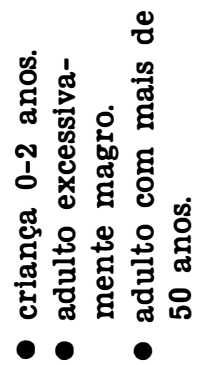

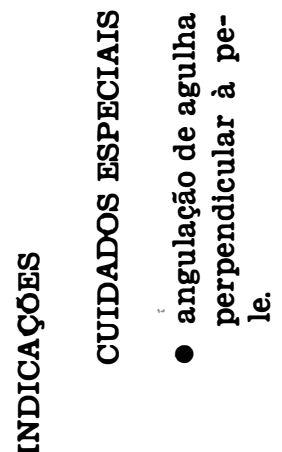

壱它完

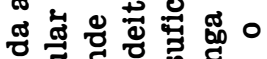

อํํㅇ ๘

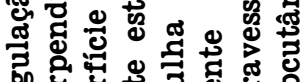

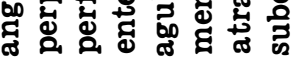

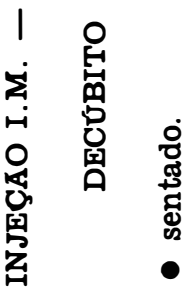

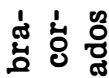

응 융

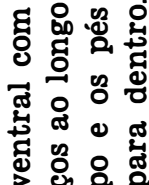

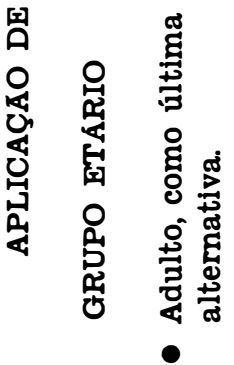

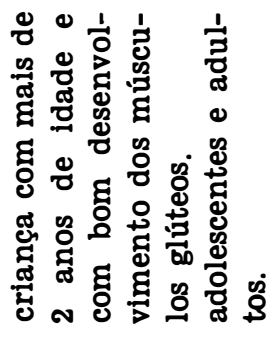

윽 윰 ๗

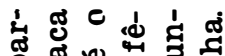

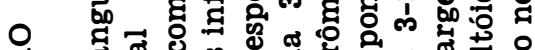

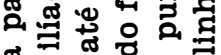

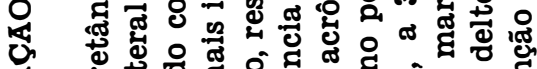

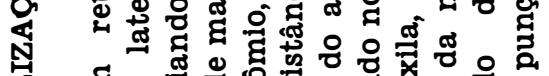

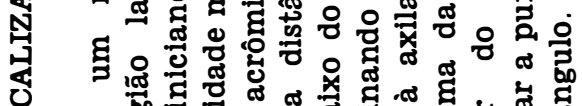
正

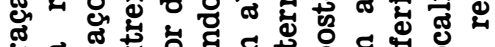

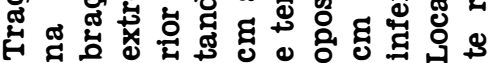

范

㶵 总

它总 


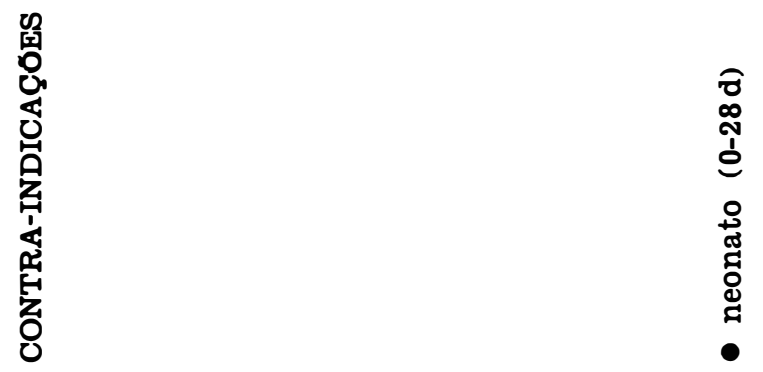

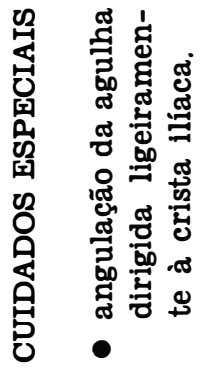

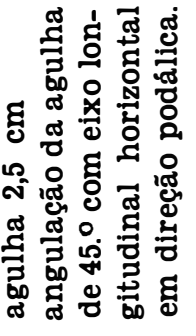

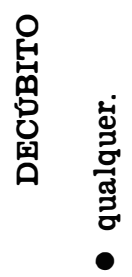

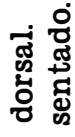

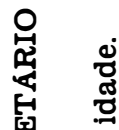

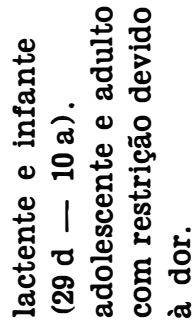

용 总

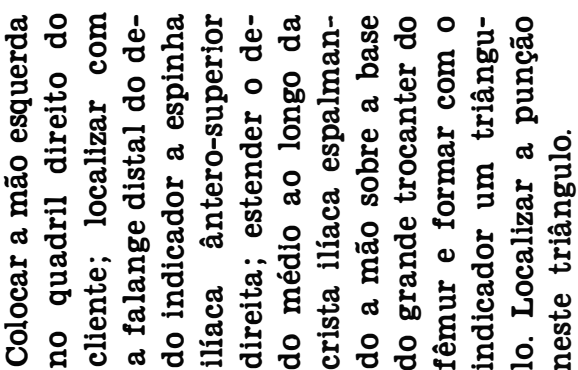

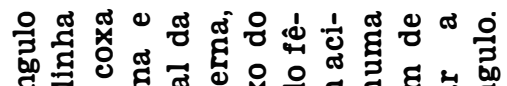
霖

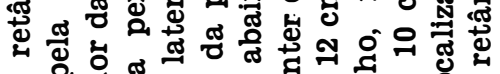
ฉ. ๙ క్ 뉴

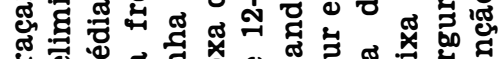

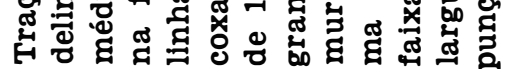

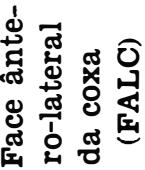


HORR, L. e colaboradoras - Determinaçāo do rendimento instrumental da ministraçåo de medicamentos por via intramuscular em paciente hospitalizados. Rev. Bras. Enf.; DF, 31 : 478-495, 1978.

ANEXO IX

GRAFICO 1 - Distribuição do tempo gasto na aplicação de injeção I.M., segundo o número de injeçōes por observação.

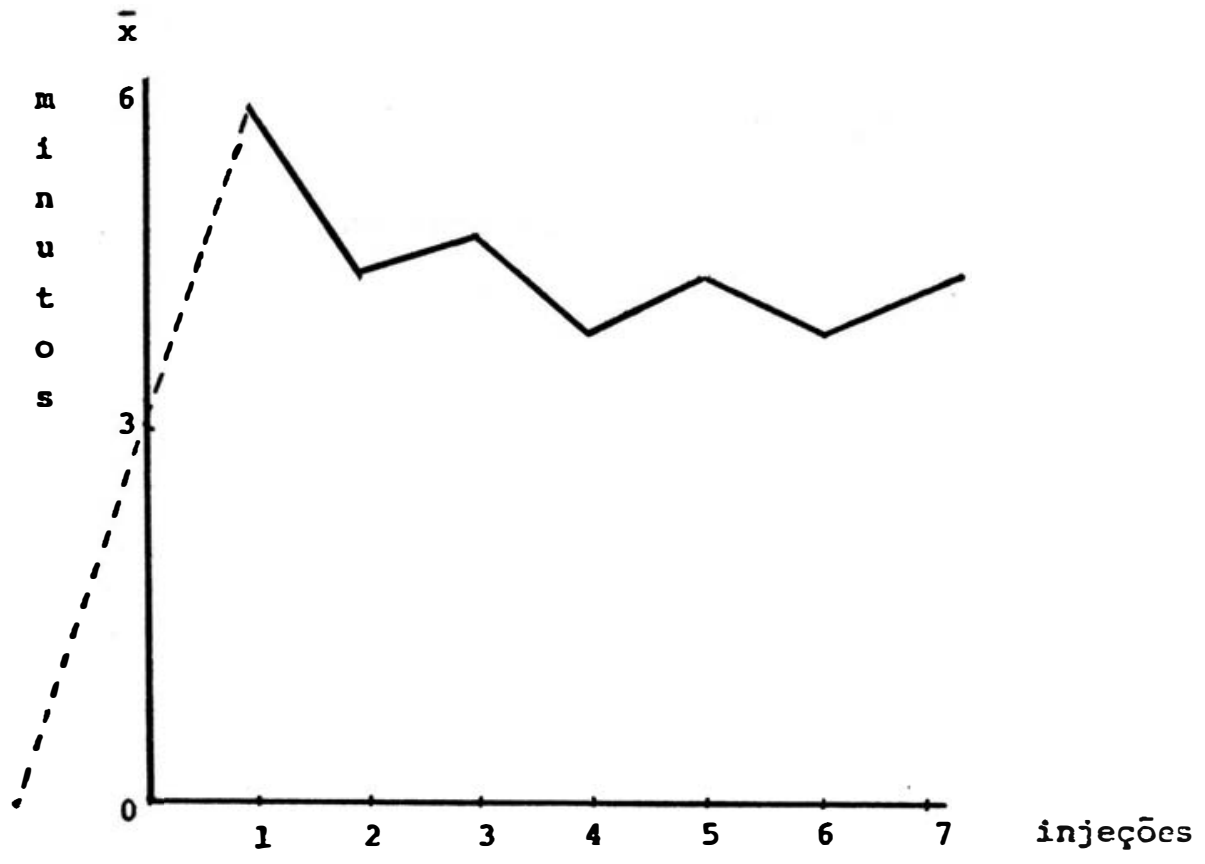

